\title{
A Review of Pharmacologic Treatment for Compulsive Buying Disorder
}

\author{
Célia Soares $^{1} \cdot$ Natália Fernandes $^{1} \cdot$ Pedro Morgado $^{1,2,3}$
}

(C) Springer International Publishing Switzerland 2016

\begin{abstract}
At present, no treatment recommendations can be made for compulsive buying disorder. Recent studies have found evidence for the efficacy of psychotherapeutic options, but less is known regarding the best pharmacologic treatment. The purpose of this review is to present and analyze the available published evidence on the pharmacological treatment of compulsive buying disorder. To achieve this, we conducted a review of studies focusing on the pharmacological treatment of compulsive buying by searching the PubMed/MEDLINE database. Selection criteria were applied, and 21 studies were identified. Pharmacological classes reported included antidepressants, mood stabilizers, opioid antagonists, second-generation antipsychotics, and $N$-methyl-D-aspartate receptor antagonists. We found only placebo-controlled trials for fluvoxamine; none showed effectiveness against placebo. Three open-label trials reported clinical improvement with citalopram; one was followed by a double-blind discontinuation. Escitalopram was effective in an open-label trial but did not show efficacy in the double-blind phase. Memantine was identified as effective in a pilot open-label study. Fluoxetine, bupropion, nortriptyline, clomipramine, topiramate and naltrexone were only reported to be effective in clinical cases. According to the available literature, there is no evidence to propose a specific pharmacologic
\end{abstract}

Célia Soares

Celia.Soares@hospitaldebraga.pt

1 Hospital de Braga, Sete Fontes, São Victor, 4710-243 Braga, Portugal

2 Life and Health Sciences Research Institute (ICVS), School of Health Sciences, University of Minho, Braga, Portugal

3 ICVS/3B's-PT Government Associate Laboratory, Braga/ Guimarães, Portugal agent for compulsive buying disorder. Future research is required for a better understanding of both pathogenesis and treatment of this disorder.

\section{Key Points}

Conducting clinical trials of treatments for compulsive buying disorder is challenging, and many limitations of current studies have been highlighted.

The heterogeneity of pharmacologic treatment options reported to be effective has raised many questions regarding our current understanding of compulsive buying disorder.

Further studies are required to examine the effectiveness of pharmacologic options against placebo and other treatments.

\section{Introduction}

Compulsive buying disorder (CBD) is a syndrome characterized by a maladaptive preoccupation with buying or shopping, or maladaptive buying or shopping impulses or behavior, that result in relevant negative personal, social, or financial consequences [1,2]. It is clinically recognized by repetitive or compulsive engagement in a behavior despite negative consequences, high impulsivity level, and diminished control over the problematic behavior [3,4]. Based on Esquirol's concept of monomania, both Kraepelin [5] and Bleuler [6] referred to CBD in their textbooks as a form of pathological impulse. The latter grouped 
compulsive buying alongside kleptomania and pyromania as an example of a "reactive impulse" or "impulsive insanity." More recently, the disorder has been receiving greater attention in a discussion shared by clinicians, psychiatry, and consumer researchers [7].

Given the multidimensional nature of $\mathrm{CBD}$, its classification is controversial and remains elusive, with researchers linking it to impulse control disorders, addictive disorders, obsessive-compulsive disorder, or the mood spectrum $[8,9]$. Other researchers have criticized both the labeling of it as an illness and the trend to medicalize behavioral problems $[10,11]$. In the perspective of a cultural background in the etiology of psychiatric disorders, CBD is a good model: without the act of buying developed in ancient Greece, and the consumer-driven economy of Western societies, no disorder would have been developed and/or maintained [11, 12]. Regarding this topic, particular attention has been given to how the digital technology age has been shaping and enhancing consumer behavior, with authors starting to look to online compulsive buying as a distinctive behavioral disorder [13, 14].

CBD is not included in current psychiatric nosological systems: Diagnostic and Statistical Manual of Mental Disorders, fifth edition (DSM-V) and International Statistical Classification of Diseases and Related Health Problems, tenth edition (ICD-10) [15, 16]. As there is no consistent concept for diagnosis, for the present work we use the diagnostic criteria of McElroy et al. [1] (Table 1).

CBD is probably a common disorder in high-income countries, with representative surveys from the USA and Germany indicating a prevalence of between 6 and $7 \%$ in adults. In a recent meta-analysis, Maraz et al. [17] estimated a prevalence of around $5 \%$ in the populations studied. A female predominance has been suggested, but there is no consensus on that issue $[18,19]$. Koran et al. [20] reported an essentially equal sex distribution in a large representative study [21]. Several studies have found relevant psychiatric comorbidities associated with CBD [22], with mood and anxiety disorders, impulse control disorders, substance abuse, and eating disorders BEING the most frequently reported [23-25]. The relevant burden of this interaction has been discussed in the literature but deserves to be clarified.

The etiology of CBD is unknown, with authors suggesting developmental, neurobiological, and cultural causal factors [26]. Neurobiological theories have proposed the presence of a disturbed serotoninergic, dopaminergic, or opioid neurotransmission, but research supporting these theories is limited. A genetic study failed to show differences in DNA sequence polymorphisms between the serotonin transporter (5-HTT) of CBD patients and controls [27]. Dopamine has been theorized to play a role in "reward dependence", but the dopamine D2 receptor gene (DRD2) that has been implicated in other addictive behaviors has not been studied in CBD [28, 29]. A study of the neural correlates of compulsive buying was conducted using functional magnetic resonance imaging, and the results showed significant differences between non-compulsive and compulsive buyers regarding brain activity in regions known to be involved in decision making [30]. In spite of increasing research, the neurobiological underpinnings of CBD remain elusive. Psychotropic medication has been widely used in CBD, supported mainly by observed similarities with phenotypes of other disorders treated with these medications (e.g., obsessive compulsive disorder $[\mathrm{OCD}])$. Despite this widespread use, there has been limited study and reporting of the effectiveness of pharmacological treatment, such that responses to these drugs remain unclear $[31,32]$. In contrast, individual and group psychotherapy, mostly cognitive-behavioral therapy (CBT), has been shown to be effective. Authors recognize it is necessary to extend the investigation in the field of psychoactive drugs [33].

The objectives of this work were to present and analyze the available published evidence on the pharmacological treatment of CBD and discuss pharmacological treatment options. We conducted a search of published articles, with no time restriction, using the PubMed/ MEDLINE database in July 2015. Keywords included oniomania, compulsive/impulsive buying, compulsive/ impulsive shopping, shopping/buying addiction crossed with the term treatment.

Table 1 Diagnostic criteria for compulsive buying disorder

(A) Maladaptive preoccupation with buying or shopping, or maladaptive buying or shopping impulses or behavior, as indicated by at least one of the following:

1. Frequent preoccupation with buying or impulses to buy that is/are experienced as irresistible, intrusive, and/or senseless

2. Frequent buying of more than can be afforded, frequent buying of items that are not needed, or shopping for longer periods of time than intended

(B) The buying preoccupations, impulses, or behaviors cause marked distress, are time consuming, significantly interfere with social or occupational functioning, or result in financial problems (e.g., indebtedness or bankruptcy)

(C) The excessive buying or shopping behavior does not occur exclusively during periods of hypomania or mania

Reproduced from McElroy et al. [1] 


\section{Literature Identified}

A total of 420 references were found through the PubMed/ MEDLINE search; 163 duplicate articles were discarded, 21 references in languages other than Portuguese, English, and Spanish were also excluded, and 218 were removed through abstract analysis for not meeting the inclusion criteria (related to Parkinson and dopamine [72 articles], related to compulsive buying disorder other than clinical trials or case studies [63 articles], limited to psychotherapeutic strategies [nine articles], and not related to the pharmacological treatment of CBD [74 articles]). A total of 21 articles were included in the review and carefully analyzed: eight clinical trials (two placebo-controlled, two open-label followed by double-blind discontinuation, and four open-label trials) and ten case studies (nine case reports and one case series). Other relevant articles were identified through the reference lists of retrieved articles (Fig. 1).

The demographic and clinical features of the studies are shown in Tables 2 and 3. Articles selected were published in the last three decades (1991-2014). The average sample size in the clinical trials was 23.75 subjects, and follow-up time ranged from 9 weeks to 12 months. Lifetime psychiatric comorbidities were reported in almost all studies analyzed. The overall sex analysis showed a female predominance.

Pharmacological classes reported included antidepressants, mood stabilizers, opioid antagonists, second-generation antipsychotics, and $N$-methyl-D-aspartate receptor antagonists. Fluvoxamine was used in six studies, two of which were placebo-controlled trials. Citalopram was tested in three open-label trials, one of which was followed by a double-blind discontinuation. Escitalopram and memantine were also studied in clinical trials. The effects of the antidepressants fluoxetine, bupropion, nortriptyline, and clomipramine have only been reported in isolated clinical cases. The same was noted with topiramate and naltrexone (Tables 2, 3).

\subsection{Antidepressants}

Seven studies reported an improvement in and/or remission of the compulsive buying behavior with antidepressant treatment, mostly serotonin reuptake inhibitors (SRIs) [1, 12, 14, 19, 34, 35, 55].

Mc Elroy et al. [34] was the first to report in the literature a clinical study of a pharmacological treatment for CBD. Based on the positive response to antidepressants seen in a number of psychiatric disorders characterized by the compulsive performance of senseless or harmful behaviors, the author reported that the

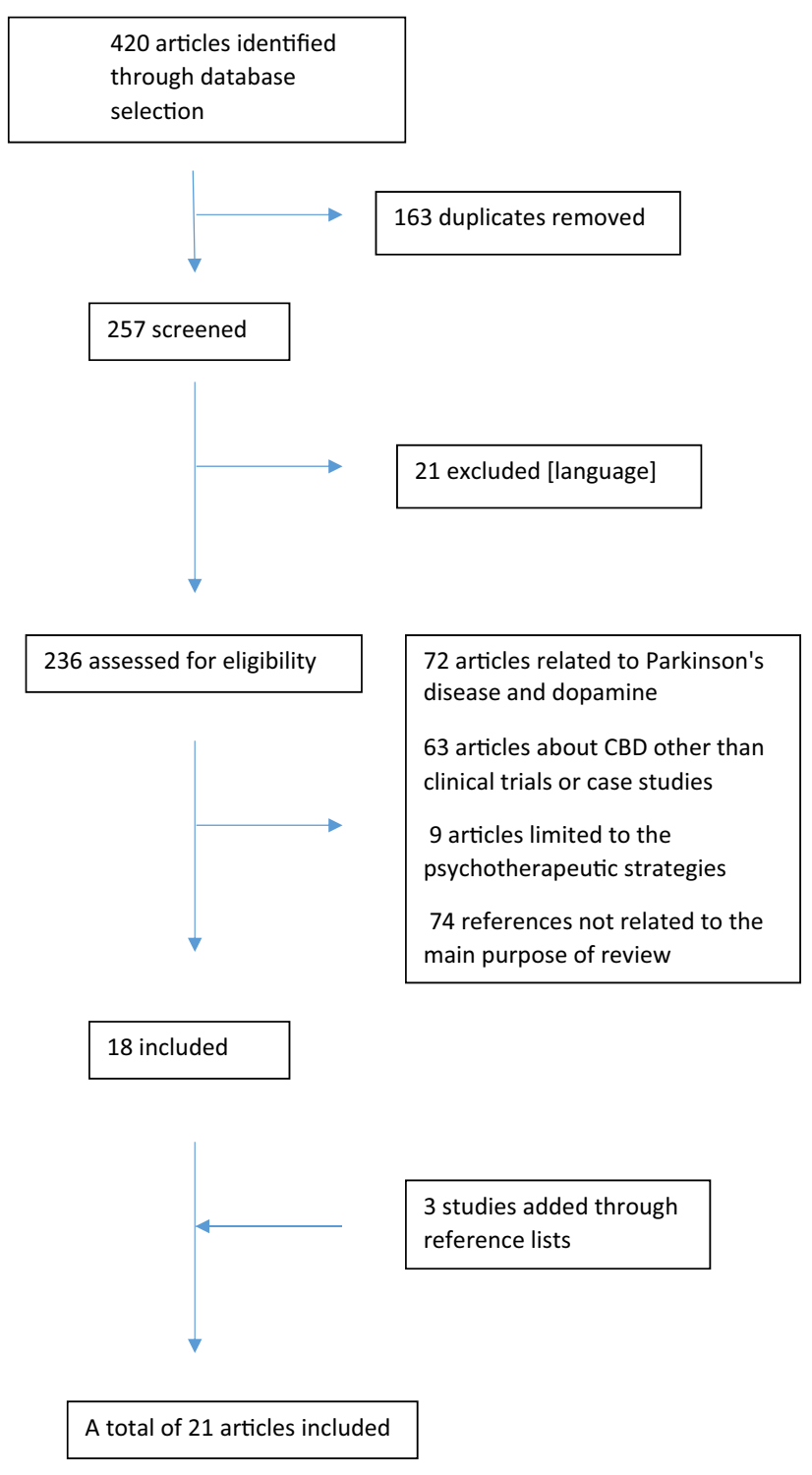

Fig. 1 The process for studies selection. $C B D$ compulsive buying disorder

compulsive buying behavior of three women with comorbid mood and anxiety disorders partially (one) or fully (two) remitted with treatment with fluoxetine, bupropion, and nortriptyline [34]. Later, in 1994, Mc Elroy et al. [1] assessed 20 compulsive buyers and found that $69 \%$ of the 13 treated with antidepressants, mostly SRIs in combination with mood stabilizers, showed reduction or remission of their buying symptoms. Two more cases of CBD in psychiatric patients in whom pathological buying behavior disappeared with the treatment of depression were reported by Lejoyeux et al. [14]. Clomipramine $150 \mathrm{mg} /$ day was used in one patient; the other agent was not reported [14]. 


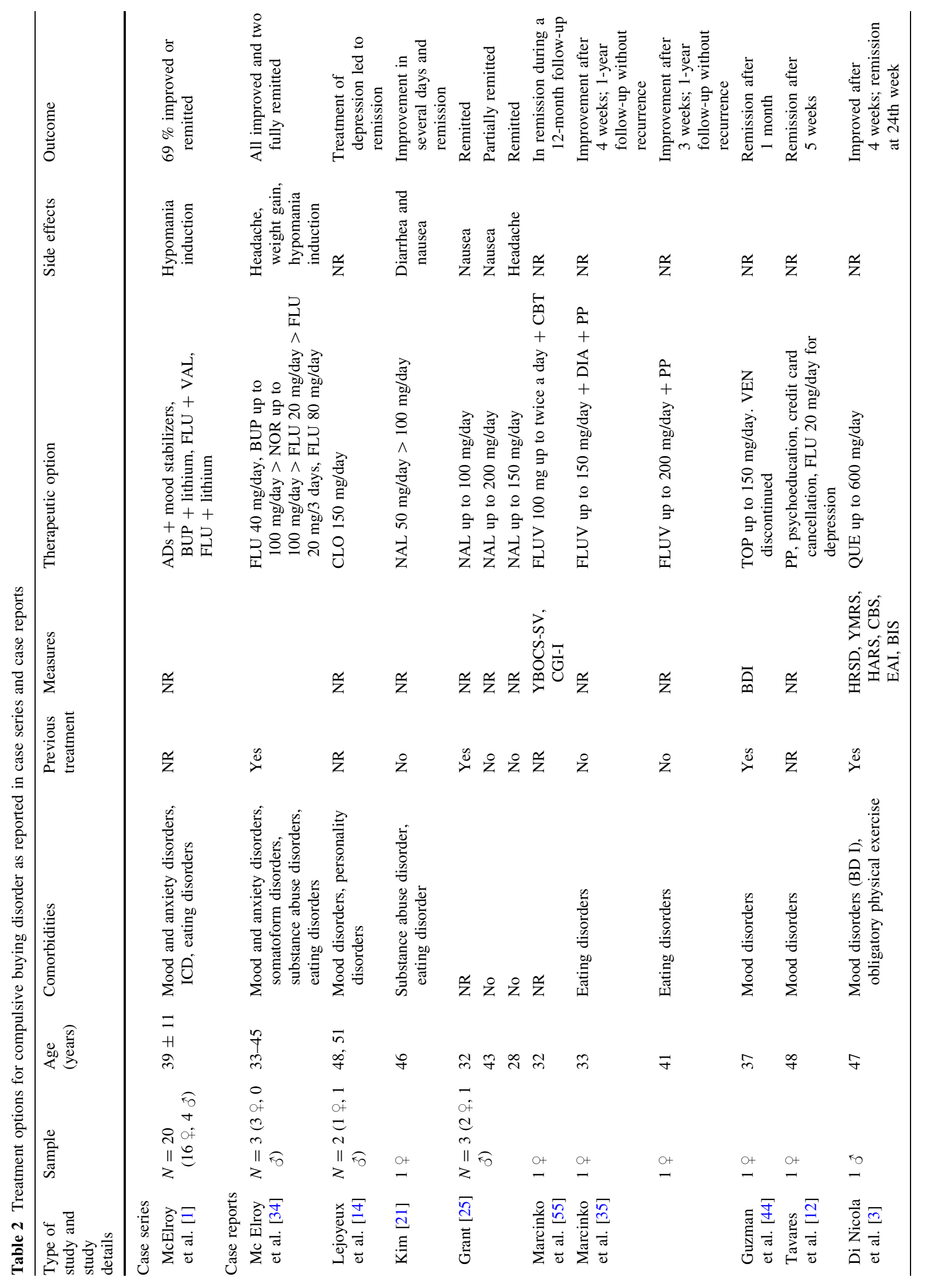




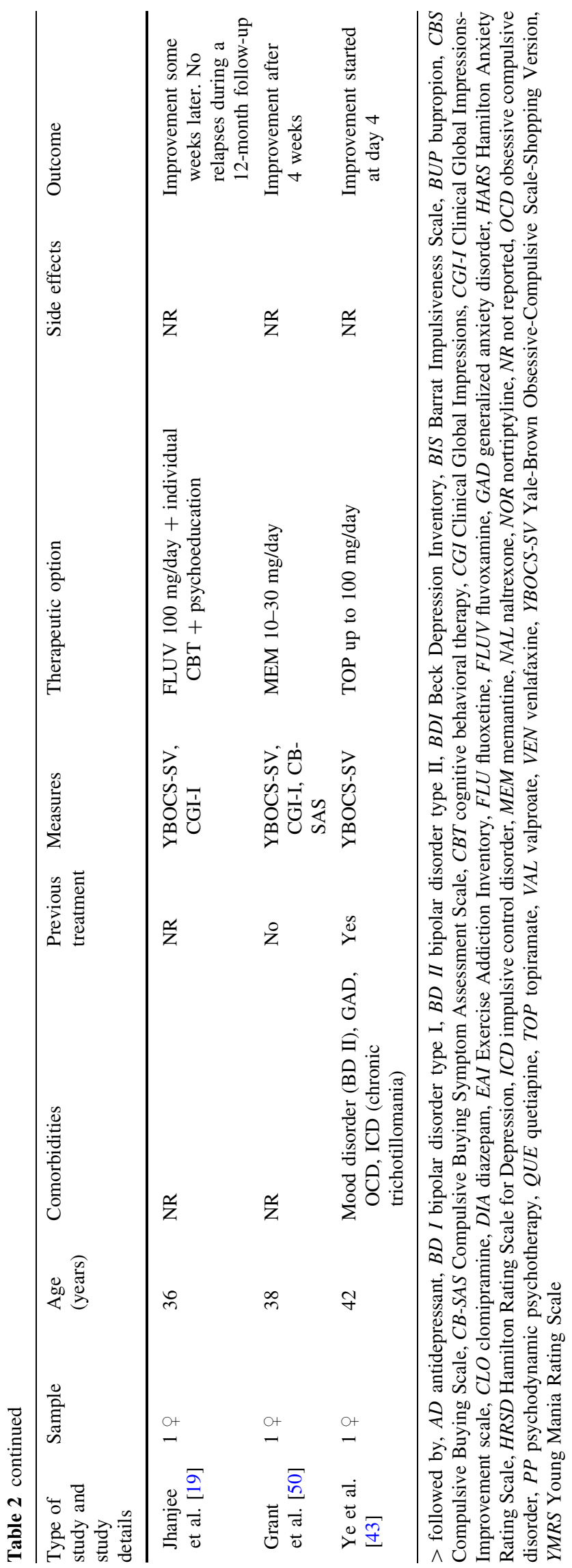

\subsubsection{Fluvoxamine}

Prompted by case reports suggesting that patients with CBD improved when receiving SRIs, and according to the comparison between this disorder and OCD, Black et al. [36] hypothesized that patients with CBD would improve in a similar way to that observed with OCD patients. An open-label trial of fluvoxamine up to $300 \mathrm{mg} /$ day was conducted, in which nine of ten subjects showed clinical improvement and a tendency to relapse when the treatment was discontinued at the end of a 9-week protocol [36]. Based on this success, Black et al. [37] later conducted a double-blind protocol to test whether fluvoxamine up to $300 \mathrm{mg} /$ day was better than placebo. The authors found no significant differences between fluvoxamine- and placebotreated subjects on any of the outcome measures, with the exception that fluvoxamine recipients achieved greater improvement than the placebo recipients on the Maudsley Obsessive-compulsive Inventory (MOI) [37].

Fluvoxamine efficacy was also evaluated in a doubleblind trial of patients with compulsive buying by Ninan et al. [38]. In this study, fluvoxamine up to $300 \mathrm{mg} /$ day significantly reduced compulsive buying during the time of active treatment, but there was a similar outcome with the placebo. Although patients who demonstrated a $>50 \%$ improvement in Yale-Brown Obsessive-Compulsive ScaleShopping Version (YBOCS-SV) scores in a 1-week singleblind placebo treatment had been excluded, there was a high placebo response rate that authors attribute to the effect of the behavioral monitoring [38].

\subsubsection{Citalopram and Escitalopram}

Following the promising results reported with fluvoxamine, Koran et al. [39] tested the effectiveness of citalopram, another selective SRI. Patients treated with citalopram up to $60 \mathrm{mg} /$ day experienced rapid, marked, and sustained improvements during a 6-month follow-up period [39]. A dose-response relationship was not present. The study was limited by the small sample, the absence of a placebo control group, and a reliance on self-reported behavior by subjects. There was a significant correlation between the change in YBOCS-SV and Montgomery-Åsberg Depression Rating Scale (MADRS) scores, which suggested that the improvement in compulsive buying behavior was due to the treatment of subclinical depressive symptoms. However, several patients achieved a sustained therapeutic response at doses lower than those used to treat depression.

Another work by Koran et al. [40] documented a 7-week open-label trial followed by a 9-week double-blind, placebo-controlled discontinuation trial. Of the 15 responders who entered the double-blind treatment phase, five of eight (63\%) randomized to placebo relapsed compared with 


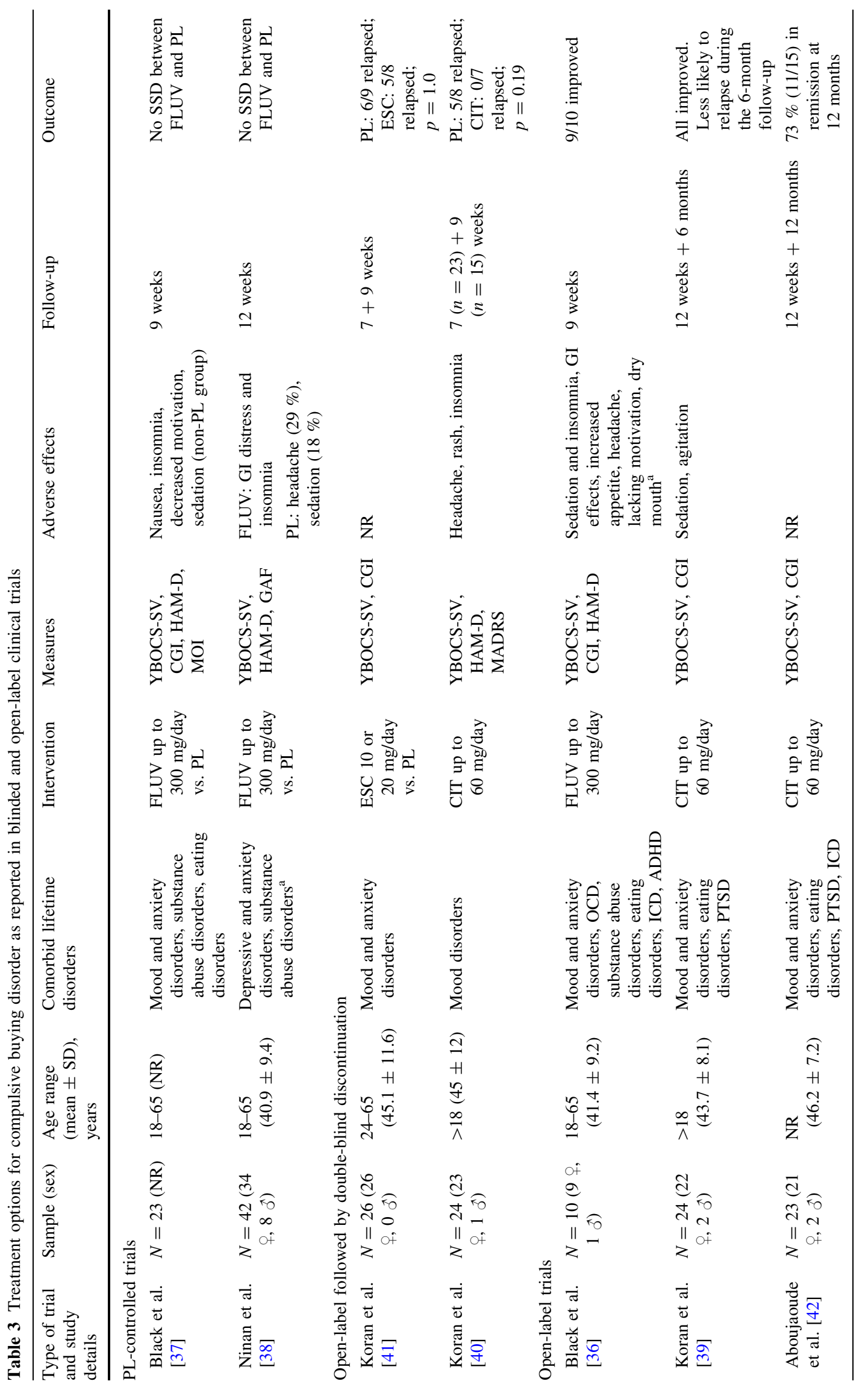




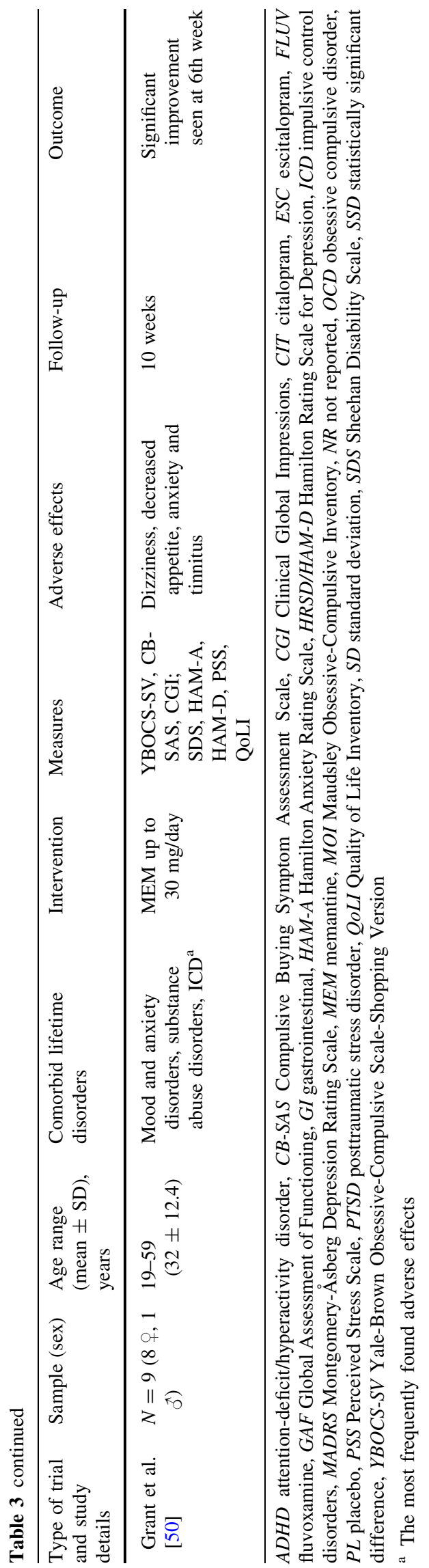

none of seven $(0 \%)$ randomized to continue taking citalopram. The reduction in shopping compulsions was independent of improvement in formally diagnosed comorbid mood disorders but positively correlated with improvement in depressive symptoms in both the open and blind phases of the study. The authors concluded that citalopram up to $60 \mathrm{mg} /$ day is an effective treatment for compulsive buying but highlight the need for placebocontrolled trials [40].

An identical study design was further conducted to test the effectiveness of escitalopram 10 or $20 \mathrm{mg} /$ day, the active isomer in the racemic mixture of citalopram [41]. The double-blind treatment phase results failed to confirm that the open-label escitalopram response was a true drug effect.

Aboujaoude et al. [42] reported the first long-term follow-up of patients with $\mathrm{CBD}$ in a cohort that had completed up to 3 months of open-label treatment with citalopram 20-60 mg/day. No clear association was found between taking citalopram and remission status, but the authors proposed that these findings do not necessarily indicate a placebo response to citalopram. Once subjects in the open-label trial gained an awareness of the disorder, they became optimistic about their ability to control it, developing new shopping strategies and motivation because of the benefits of remission. Alternatively, they speculate that 3 months of citalopram treatment can normalize serotoninergic neural pathways. The authors concluded that an acute response to citalopram predicts a greater likelihood of continued remission over 1 year [42].

\subsection{Opioid Antagonists}

\subsubsection{Naltrexone}

Naltrexone, an opioid antagonist that inhibits dopamine release in the nucleus accumbens, was reported to reduce urges to shop and compulsive shopping behavior by Kim [21]. The authors prescribed the drug for up to 9 months to 15 patients with impulse-control disorders, including in this group patients with CBD [21].

Later, Grant [25] reported three cases of patients with CBD without any other comorbidity who were successfully treated with high doses of naltrexone (up to 100, 150, and $200 \mathrm{mg} /$ day). The author suggested that the antagonism of the system that processes pleasure and pain can diminish an essential feature of CBD: the failure to resist an impulse to purchase despite harmful consequences [25]. The author advised that liver function tests should be monitored in all patients taking naltrexone.

No open or double-blind trials were conducted with this agent to confirm these findings. 


\subsection{Mood Stabilizers}

\subsubsection{Topiramate}

Two case reports were published on the treatment of CBD with topiramate [43, 44]. Topiramate is an active anticonvulsant whose mechanisms of action include potentiation of gamma-aminobutyric acid (GABA) to activate GABA-A receptors and antagonism of glutamate at specific receptors. It has been shown to be beneficial for a variety of psychiatric illnesses, such as affective disorders, eating disorders, addictive disorders (including alcoholism), posttraumatic stress disorder, and OCD [45-49]. The use of topiramate up to $150 \mathrm{mg} /$ day in CBD was first suggested by Guzam et al. [44], who highlighted the role of this agent in the treatment of addictive behavior disorders. Later, Ye et al. [43] reported another case treated in a similar way, in which a patient maintained progress for more than half a year. The improvement in compulsive buying behavior was independent of comorbid conditions; the advantage with topiramate is that it can be quickly titrated [43]. The authors suggested that this agent can be an alternative strategy to the modulation of serotonin, glutamate, and opioid systems. As yet, no clinical trials have been conducted.

\subsection{Other Pharmacologic Options}

\subsubsection{Quetiapine}

Quetiapine is a second-generation antipsychotic that shows affinity for various neurotransmitter receptors. Specifically, the D1 and D2 dopamine receptor, the alpha-1 and alpha-2 adrenergic receptor, and 5-HT1A and 5-HT2 serotonin receptor subtypes are antagonized. Di Nicola et al. [3] documented a case of bipolar I disorder with comorbid compulsive buying disorder and physical exercise addiction that was successfully treated with quetiapine up to $600 \mathrm{mg} /$ day. The authors highlighted that the assessment of behavioral addictions, such as CBD, in bipolar disorder patients may have a direct impact on the choice of pharmacological and psycho-educative interventions. The role of impulsivity and personality dimensions in bipolar disorder is reinforced.

\subsubsection{Memantine}

In a pilot open-label trial, Grant et al. [50] tested the agent memantine, an $N$-methyl-D-aspartate receptor antagonist that appears to reduce glutamate excitability and improve impulsive behaviors. Treatment with memantine 10-30 mg/day was associated with diminished impulsive buying and improvements in cognitive tasks of impulsivity.
In addition, the medication was well-tolerated. The authors concluded that pharmacologic manipulation of the glutamate system may target the impulsive behavior underlying CBD in a subtype of patients [50].

\section{Discussion}

This review shows a predominance of case reports (vs. clinical trials) and heterogeneous reported pharmacological treatment options. This may be due to our limited understanding of CBD, particularly considerations of classification and neurobiological correlates. Discussion on the topic has raised many questions [37, 38, 41] including the following: is CBD a symptom complex seen in several conditions rather than a separate syndrome? If we consider it as a distinctive disorder, could it be more related to mood, obsessive-compulsive, impulse control disorders, or an addictive spectrum? Is compulsive buying a single construct or has it multiple subtypes or varying roots in the same individual? Do patients respond preferentially to medication or to behavior therapy within the same subtype?

Neurobiological theories have proposed the presence of a disturbed serotoninergic, dopaminergic, or opioid neurotransmission, which could probably explain the positive outcome seen with antidepressants or opioid antagonists, but research to support these assumptions is limited and, to date, the psychotropic medications used in CBD are supported mainly by observed or hypothetical similarities with phenotypes of other treatable disorders and concomitant comorbidities.

\subsection{Compulsive Buying Disorder (CBD) and Mood Disorders}

The prevalence studies showing a high prevalence of comorbid mood disorders in CBD patients, observations that shopping and spending have antidepressant effects, and reports of compulsive buying responding to antidepressants have supported a causal link between mood disorders and CBD [14, 22, 34]. However, further studies with non-depressed patients and cases in which the disorders showed unrelated outcomes have placed this hypothesis in question [12, 40]. The role of mood symptoms in the initiation, continuance, and relief of this disorder warrants further investigation.

The effectiveness of antidepressants in CBD patients with and without comorbid mood disorder has been widely described in case reports, case series, and open-label trials (Tables 2, 3). However, the only two double-blind trials conducted showed no statistical differences between the treated and the placebo groups $[37,38]$. 
Two case reports suggested that topiramate might be useful for CBD with comorbid bipolar disorder or depression, but no controlled studies have been conducted to confirm these findings [43, 44]. Quetiapine was also documented to be effective in a single case report of a patient with comorbid bipolar disorder and was suggested to be a recommended alternative for similar patients [3].

\subsection{CBD and Obsessive Compulsive Disorder}

Despite being neither egodystonic nor ritualized, the buying impulses and buying behavior, respectively, have similarities to the obsessions and compulsions of OCD, and some researchers have proposed that $\mathrm{CBD}$ can be placed in the spectrum of disorders linked to OCD [8]. The similarities between these conditions suggested that medication used to treat OCD would also be useful to treat CBD, and several SRIs have been tested. However, placebo-controlled studies failed to show statistically significant differences between CBD patients treated with fluvoxamine, an antidepressant shown to be effective in OCD patients, and placebo $[37,38]$.

\subsection{CBD, Other Impulse Control Disorders, and Behavioral Addictions}

A link has been suggested between CBD and the irresistible impulses and impulse actions of impulse control disorders and the drug urges and drug use of substance use disorders [1].

Given the shared common neurobiological mechanisms between substance and behavior addictions, through the activation of the reward pathways and the involvement of multiple neurotransmitter systems (dopaminergic, endogenous opioids, and serotoninergic), opioid antagonists have been investigated for the treatment of CBD [51]. Improvement was reported, but no clinical trials were conducted $[21,25]$.

A recent study has suggested that pharmacologic modulation of the glutamate system may reduce behaviors associated with CBD by improving neurocognitive function targeting inhibiting control mechanisms that result in shopping behavior despite adverse consequences. The authors hypothesized that a subtype of patients with CBD and impaired inhibitory control may respond preferentially to memantine [50].

\subsection{Psychiatric Comorbid Disorders}

The studies identified show a high prevalence of comorbid psychiatric disorders, the concurrent treatment of which should be considered on an individual basis to ameliorate the final outcome $[41,52,53]$.
To do so, a complete psychiatric history including a screening of comorbidities is a priority in the treatment of CBD patients. The previous treatment approaches should also be assessed and the individual characteristics noted. Depending on the comorbidity associated, different pharmacological approaches can be considered. For example, for a patient with comorbid depression, anxiety, or OCD features, the antidepressants fluvoxamine or citalopram may be valid options; in the presence of an impulse control disorder or substance abuse disorder, topiramate or naltrexone may be used.

\subsection{CBD and Adjuvant Treatments}

According to reports from double-blind studies, psychotherapeutic approaches should be combined. Mueller et al. [54] conducted a randomized trial to characterize the efficacy of CBT, and results revealed significant differences between the groups receiving CBT and the control groups on the primary outcome variables established. The improvement was maintained during the 6-month followup, and authors concluded that a disorder-specific cognitive-behavioral intervention can significantly impact compulsive buying behavior [54]. Other non-pharmacological strategies should also be applied (e.g., self-help programs, Debtors Anonymous, financial counseling) [2].

\subsection{Limitations of Current Studies}

Conducting trials in individuals with impulse control disorders is challenging, and limitations of the studies identified should be noted. Researchers mentioned the use of different criteria to identify "illness" and response, the small sample sizes, and the similar drug and placebo responses as relevant limitations.

Because of a high placebo response, open-label trials can have a potential bias toward effectiveness, whereas double-blind trials can measure the true effect of the active treatment. The high placebo response rate seen in controlled studies is probably explained by a tendency to reduce the compulsive behavior when greater attention is given to it. In open-label trials followed by a double-blind discontinuation phase, the selection of subjects for the study with a high level of interest in the acquired benefit in the first open-label phase could have led to the improvement without medication in the double-blind phase [36].

There is limited information on the hypothesis of a doseresponse relationship and the point at which the pharmacological treatment can be safely discontinued. The dosage required for optimal response and maintenance therapy needs further study.

Additional work is needed to determine which ingredient of the treatment experimental approach is most 
therapeutic, and more work is needed to show the superiority of medication over placebo with and without other psychotherapeutic approaches. Longer follow-up pharmacologic studies with bigger and less restricted samples are warranted.

The role of mood symptoms in the course of compulsive buying symptoms (beginning, maintenance, and remission) also warrants further investigation.

\subsection{Future Research}

Future research should focus on the understanding of disease pathogenesis and pathophysiology. Neurobiological research on neurotransmitters in $\mathrm{CBD}$, with the measurement of plasma or cerebral spinal fluid levels, would be useful in this regard.

There is a need for better diagnostic instruments to standardize clinical criteria in experimental studies, and the relationship between comorbid conditions and CBD deserves greater understanding.

As mentioned, there are no adequate data on the longitudinal course of CBD, so longer follow-up placebo-controlled studies should be conducted.

\section{Conclusions}

The reviewed literature suggest pharmacological interventions may be effective for CBD. However, the positive results of pharmacological treatment have not yet been confirmed in controlled trials.

Most authors agree that the individual characteristics of the patient (comorbidities, previous medications, self-tolerance) will guide the choice of a personalized pharmacological treatment. Future research on neurobiological, psychological, and sociocultural factors will definitely add to this approach.

Further trials are warranted to find evidence-based therapeutic recommendations.

Acknowledgments The authors would like to thank Adam Mieczyński and Marina Gonçalves for their help with translation.

\section{Compliance with Ethical Standards}

The authors declare that all principles of ethical and professional conduct have been followed. The research did not involve human participants or animals.

Conflict of interest Célia Soares, Natália Fernandes, and Pedro Morgado declare they have no conflicts of interest.

Funding The authors certify that neither they nor their institutions received any financial support to assist with the preparation of this review.

\section{References}

1. McElroy SL, Keck PE Jr, Pope HG Jr, Smith JM, Strakowski SM. Compulsive buying: a report of 20 cases. J Clin Psychiatry. 1994;55(6):242-8.

2. Black DW. A review of compulsive buying disorder. World Psychiatry. 2007;6(1):14-8.

3. Di Nicola M, Martinotti G, Mazza M, Tedeschi D, Pozzi G, Janiri L. Quetiapine as add-on treatment for bipolar I disorder with comorbid compulsive buying and physical exercise addiction. Prog Neuropsychopharmacol Biol Psychiatry. 2010;34(4):713-4.

4. Lejoyeux M, Ades J, Tassain V, Solomon J. Phenomenology and psychopathology of uncontrolled buying. Am J Psychiatry. 1996;153(12):1524-9.

5. Kraepelin E. Psychiatrie: Ein Lehrbuch für Studierende und Ärzte. Leipzig: Johann Ambrosius Barth; 1909.

6. Bleuler E. Textbook of psychiatry. New York: The Macmillan company; 1934.

7. Faber RJ, O'Guinn TC, Krych R. Compulsive consumption. Adv Consum Res. 1987;14:132-5.

8. Black DW, Shaw M, Blum N. Pathological gambling and compulsive buying: do they fall within an obsessive-compulsive spectrum? Dialog Clin Neurosci. 2010;12(2):175-85.

9. McElroy SL, Keck PE Jr, Phillips KA. Kleptomania, compulsive buying, and binge-eating disorder. J Clin Psychiatry. 1995;56(Suppl 4):14-26 (discussion 7).

10. Lee S, Mysyk A. The medicalization of compulsive buying. Soc Sci Med. 2004;58(9):1709-18.

11. Hartston HJ, Koran LM. Impulsive behavior in a consumer culture. Int J Psychiatry Clin Pract. 2002;6(2):65-8.

12. Tavares H, Lobo DS, Fuentes D, Black DW. Compulsive buying disorder: a review and a case vignette. Rev Bras Psiquiatr. 2008;30(Suppl 1):S16-23.

13. Aboujaoude E, Starcevic V. Mental Health in the Digital Age: Grave Dangers, Great Promise. Oxford: Oxford University; 2015.

14. Lejoyeux M, Hourtane M, Ades J. Compulsive buying and depression. J Clin Psychiatry. 1995;56(1):38.

15. American Psychiatric Association. Diagnostic and statistical manual of mental disorders. 5th ed. Arlington: American Psychiatric Association; 2013.

16. World Health Organization. International statistical classification of diseases and related health problems. 10th revision. Geneva: WHO; 2010.

17. Maraz A, Griffiths MD, Demetrovics Z. The prevalence of compulsive buying: a meta-analysis. Addiction (Abingdon, England). 2016;111(3):408-19.

18. Dell'Osso B, Allen A, Altamura AC, Buoli M, Hollander E. Impulsive-compulsive buying disorder: clinical overview. Aust NZ J Psychiatry. 2008;42(4):259-66.

19. Jhanjee A, Kumar P, Bhatia MS, Shrivastava S, Bhatnagar N, Kumar V. Oniomania-successful treatment with fluvoxamine and cognitive-behavioral psychotherapy. Delhi Psychiatry J. 2010;13(1):147-9.

20. Koran LM, Faber RJ, Aboujaoude E, Large MD, Serpe RT. Estimated prevalence of compulsive buying behavior in the United States. Am J Psychiatry. 2006;163(10):1806-12.

21. Kim SW. Opioid antagonists in the treatment of impulse-control disorders. J Clin Psychiatry. 1998;59:159-64.

22. Christenson GA, Faber RJ, de Zwaan M, Raymond NC, Specker SM, Ekern MD, et al. Compulsive buying: descriptive characteristics and psychiatric comorbidity. J Clin Psychiatry. 1994;55(1):5-11.

23. Black DW. Compulsive buying disorder: definition, assessment, epidemiology and clinical management. CNS Drugs. 2001;15(1):17-27. 
24. Bleuler E. Textbook of psychiatry. New York: Macmillan; 1930.

25. Grant JE. Three cases of compulsive buying treated with naltrexone. Int J Psychiatry Clin Pract. 2003;7:223-5.

26. Black DW. Compulsive buying disorder: a review of the evidence. CNS Spectr. 2007;12(2):124-32.

27. Devor EJ, Magee HJ, Dill-Devor RM, Gabel J, Black DW. Serotonin transporter gene (5-HTT) polymorphisms and compulsive buying. Am J Med Genetics. 1999;88(2):123-5.

28. Blum K, Sheridan PJ, Wood RC, Braverman ER, Chen TJ, Comings DE. Dopamine D2 receptor gene variants: association and linkage studies in impulsive-addictive-compulsive behaviour. Pharmacogenetics. 1995;5(3):121-41.

29. Holden C. 'Behavioral' addictions: do they exist? Science (New York, NY). 2001;294(5544):980-2.

30. Gerhard Raab CEE. Michael neuner, bernd weber. a neurological study of compulsive buying behaviour. J Consum Policy. 2011;34(4):401-13.

31. Mueller A, de Zwaan M. Treatment of compulsive buying. Fortschr Neurol Psychiatr. 2008;76(8):478-83.

32. Bullock K, Koran L. Psychopharmacology of compulsive buying. Drugs Today (Barc). 2003;39(9):695-700.

33. Lourenco Leite P, Pereira VM, Nardi AE, Silva AC. Psychotherapy for compulsive buying disorder: a systematic review. Psychiatry Res. 2014;219(3):411-9.

34. McElroy SL, Satlin A, Pope HG, Keck PE, Hudson JI. Treatment of compulsive shopping with antidepressants: a report of three cases. Ann Clin Psychiatry. 1991;3(3):199-204.

35. Marcinko D, Bolanca M, Rudan V. Compulsive buying and binge eating disorder-a case vignettes. Prog Neuropsychopharmacol Biol Psychiatry. 2006;30(8):1542-4.

36. Black DW, Monahan P, Gabel J. Fluvoxamine in the treatment of compulsive buying. J Clin Psychiatry. 1997;58(4):159-63.

37. Black DW, Gabel J, Hansen J, Schlosser S. A double-blind comparison of fluvoxamine versus placebo in the treatment of compulsive buying disorder. Ann Clin Psychiatry. 2000;12(4):205-11.

38. Ninan PT, McElroy SL, Kane CP, Knight BT, Casuto LS, Rose $\mathrm{SE}$, et al. Placebo-controlled study of fluvoxamine in the treatment of patients with compulsive buying. J Clin Psychopharmacol. 2000;20(3):362-6.

39. Koran LM, Bullock KD, Hartston HJ, Elliott MA, D'Andrea V. Citalopram treatment of compulsive shopping: an open-label study. J Clin Psychiatry. 2002;63(8):704-8.

40. Koran LM, Chuong HW, Bullock KD, Smith SC. Citalopram for compulsive shopping disorder: an open-label study followed by double-blind discontinuation. J Clin Psychiatry. 2003;64(7):793-8.
41. Koran LM, Aboujaoude EN, Solvason B, Gamel NN, Smith EH. Escitalopram for compulsive buying disorder: a double-blind discontinuation study. J Clin Psychopharmacol. 2007;27(2):225-7.

42. Aboujaoude E, Gamel N, Koran LM. A 1-year naturalistic follow-up of patients with compulsive shopping disorder. J Clin Psychiatry. 2003;64(8):946-50.

43. Ye L, Kadia S, Lippmann S. Topiramate and compulsive buying disorder. J Clin Psychopharmacol. 2014;34(1):174-5.

44. Guzman CS, Filomensky T, Tavares H. Compulsive buying treatment with topiramate, a case report. Rev Bras Psiquiatr. 2007;29(4):383-4.

45. Reas DL, Grilo CM. Pharmacological treatment of binge eating disorder: update review and synthesis. Expert Opin Pharmacother. 2015;16(10):1463-78.

46. Chengappa KN, Rathore D, Levine J, Atzert R, Solai L, Parepally $\mathrm{H}$, et al. Topiramate as add-on treatment for patients with bipolar mania. Bipolar Disord. 1999;1(1):42-53.

47. Berlant JL. Topiramate in posttraumatic stress disorder: preliminary clinical observations. J Clin Psychiatry. 2001;62(Suppl 17):60-3.

48. Guglielmo R, Martinotti G, Quatrale M, Ioime L, Kadilli I, Di Nicola M, et al. Topiramate in alcohol use disorders: review and update. CNS Drugs. 2015;29(5):383-95.

49. Afshar H, Akuchekian S, Mahaky B, Zarean E. Topiramate augmentation in refractory obsessive-compulsive disorder: a randomized, double-blind, placebo-controlled trial. J Res Med Sci. 2014;19(10):976-81.

50. Grant JE, Odlaug BL, Mooney M, O’Brien R, Kim SW. Openlabel pilot study of memantine in the treatment of compulsive buying. Ann Clin Psychiatry. 2012;24(2):119-26.

51. Potenza MN. Review. The neurobiology of pathological gambling and drug addiction: an overview and new findings. Philos Trans R Soc Lond B Biol Sci. 2008;363(1507):3181-9.

52. Muller A, Mitchell JE, de Zwaan M. Compulsive buying. Am J Addict. 2015;24(2):132-7.

53. Black DW. Compulsive buying: a review. J Clin Psychiatry. 1996;57(Suppl 8):50-4 (discussion 5).

54. Mueller A, Mueller U, Silbermann A, Reinecker H, Bleich S, Mitchell JE, et al. A randomized, controlled trial of group cognitive-behavioral therapy for compulsive buying disorder: posttreatment and 6-month follow-up results. J Clin Psychiatry. 2008;69(7):1131-8.

55. Marcinko D, Karlovic D. Oniomania: successful treatment with fluvoxamine and cognitive-behavioral psychotherapy. Psychiatria Danubina. 2005;17(1-2):97-100. 